Post-print of: Food Research International 76. 645-653 (2015)

\title{
Assessment of the differences in the phenolic composition and color characteristics of new strawberry (Fragaria $x$ ananassa Duch.) cultivars by HPLC-MS and Imaging Tristimulus Colorimetry
}

\author{
Rebeca Fernández-Lara ${ }^{\mathrm{a}}$, Belén Gordillo ${ }^{\mathrm{b}}$, Francisco J. Rodríguez-Pulido ${ }^{\mathrm{b}}$, M. Lourdes González-Miret ${ }^{\mathrm{b}}$, \\ Alma A. del Villar-Martínez ${ }^{\text {c }}$, Gloria Dávila-Ortiz ${ }^{\text {a }}$, Francisco J. Heredia b,* \\ a Escuela Nacional de Ciencias Biológicas, Instituto Politécnico Nacional, Prol. Carpio, Esq. Plan de Ayala S/N, Col. Casco de Santo Tomás, Del. Miguel Hidalgo, C.P. 11340 México, D.F., Mexico \\ ${ }^{\mathrm{b}}$ Food Colour E' Quality Laboratory, Dept. Nutrition E' Food Science, Universidad de Sevilla, 41012 Sevilla, Spain \\ c Centro de Desarrollo de Productos Bióticos, Instituto Politécnico Nacional, Calle CEPROBI No 8 Col. San Isidro, C.P. 62731 Yautepec, Mor., Mexico
}

\section{Keywords:}

Strawberry

New cultivars

Anthocyanin

Color

Imaging Tristimulus Colorimetry

\begin{abstract}
A B S T R A C T
The phenolic composition (by HPLC-DAD-MS) and color characteristics (by Imaging Tristimulus Colorimetry) of four strawberry cultivars that have shown good climate adaptation to subtropical area (Nikte, Zamorana, Jacona and Pakal) have been assessed. 24 monomeric phenolics were identified, including 15 anthocyanins, 5 phenolic acids, 1 flavanol and 4 flavonols. Nikte and Zamorana showed the highest phenolic potential mainly due to their higher content of anthocyanins, while Pakal was richer in phenolic acids. Regarding color, Nikte and Zamorana were the more similar cultivars having the lowest values of lightness and hue. On the contrary, the color of Pakal was quite different from all the rest, due to the specific distribution between pelargonidin and cyanidin. The inclusion of both phenolic and colorimetric information in the Linear Discriminant Analysis allowed reaching very good discriminations among cultivars.
\end{abstract}

\section{Introduction}

Strawberry (Fragaria $x$ ananassa Duch.) is one of the most economically important cultivated berry fruit crops worldwide with more than 7.5 million tonnes produced in 2013 (Faostat, 2015). Currently, strawberry is considered as a "functional food" due to the multiple preventive and therapeutic health benefits associated with its consumption (Basu, Nguyen, Betts, \& Lyons, 2014). The nutritional value of strawberry fruits is in part attributed to their high content of phytochemicals, mostly represented by phenolic compounds. In fact, strawberry is ranked no. 9 on the list of 100 richest sources of dietary phenols, providing $390 \mathrm{mg}$ of total phenols per serving (Pérez-Jiménez, Neveu, Vos, \& Scalbert, 2010). The importance of dietary phenols derives from the evidence of their high antioxidant activity. In this regard, previous investigations

Abbreviations: (HPLC-DAD-MS), high performance liquid chromatography coupled to diode array detection and mass spectrometry; (DW), dry weight; (RGB), red, green, blue; (LDA), linear discriminant analysis.

* Corresponding author at: Food Colour \& Quality Lab., Dept. Nutrition \& Food Science, Facultad de Farmacia, Universidad de Sevilla, 41012 Sevilla, Spain.

E-mail addresses: rebe.fdz@outlook.com (R. Fernández-Lara),bgordillo@us.es (B. Gordillo), rpulido@us.es (F.J. Rodríguez-Pulido), miret@us.es (M. Lourdes González-Miret), adelvillarm@ipn.mx (A.A. del Villar-Martínez), gdavilao@yahoo.com (G. Dávila-Ortiz), heredia@us.es (F.J. Heredia). stated that phenolic compounds are the main bioactive constituents responsible for the antioxidant properties of strawberries, rather than other antioxidants as vitamin (Sun, Chu, Wu, \& Liu, 2002). Besides antioxidant capacity, strawberry phenolics are thought to be involved in diverse biological activities related to cellular metabolism and cellular survival. Thus, they could act as chemopreventive agents that exert protective effects on human health by preventing chronic diseases such as some types of cancer (Giampieri, Alvarez-Suarez, \& Battino, 2014).

Likewise, phenolics continue attracting much attention because some of these compounds are directly responsible for important organoleptic properties of strawberry fruits including taste, flavor, aroma, color and appearance (Holzwarth, Korhummel, Carle, \& Kammerer, 2012). In particular, color and appearance play a significant role in food acceptance because visual appreciation is the first impression of quality that consumers normally experience (De Bruijn \& Bórquez, 2014; Hutchings \& Luo, 2002, Chap. 12). In this sense, fresh strawberries are highly appreciated for their attractive bright red color, which is associated with the preservation of their natural quality (Bursac Kovacevic et al., 2015).

For these reasons, the high variety of phenolics present in strawberries from diverse origins has been studied in a large extent (Aaby, Mazur, Nes, \& Skrede, 2012; Hernanz, Recamales, Meléndez-Martínez, Gonzalez-Miret, \& Heredia, 2007; Lopes da Silva, Escribano-Bailón, 
Pérez Alonso, Rivas-Gonzalo, \& Santos-Buelga, 2007). Quantitatively, one of the main subclasses of flavonoids are anthocyanins, which determine the colored pigmentation of fruits. Values of $150-600 \mathrm{mg} / \mathrm{kg}$ fresh weight of anthocyanins have been reported, being the glycosides of pelargonidin and cyanidin the most representative colored compounds (Giampieri et al., 2014). Moreover, strawberries contain high amounts of many beneficial colorless phenolics such as ellagic acid, $p$-coumaric acid, caffeic acid, flavanols, or glycosides of quercetin and kaempferol, whose distribution differs among varieties (Häkkinen et al., 1999; Häkkinen \& Törrönen, 2000; Hernanz et al., 2007; Landete, 2011; Aaby et al., 2012).

According to the Food and Agriculture Organization of the United Nations, continued increases in worldwide strawberry consumption indicates that the future of strawberry production and sales is very promising (Faostat, 2015). Under these circumstances, a new trend aimed at implementing new strawberry genotypes has been observed, which is being possible thanks to the important investments in biotechnological applications and cross-breeding programs with different Fragaria species (Qin, Teixeira da Silva, Zhang, \& Zhang, 2008). These innovative approaches are intended to improve agronomical traits of cultivated strawberries like the resistance or tolerance to biotic and abiotic stresses, propagation capacity, yield potential, ripening time, and other related factors (Bestfleisch, Möhring, Hanke, Peil, \& Flachowsky, 2014). Furthermore, it has been demonstrated that these alternative practices are able to increase the content of specific phytochemicals in strawberry fruits, and consequently ameliorate their nutritional value and sensorial properties (Diamanti et al., 2014).

In the last years, Mexico has been consolidated as one of the principal suppliers of fresh fruits and vegetables. In this context, the Mexican strawberry industry has gained great importance and dynamism since the favorable climate conditions have allowed developing specific cross-breeding programs and new strawberry varieties are being cultivated and introduced into trade (Dávalos-González, NarroSánchez, Jofre-Garfías, Vázquez-Sánchez, \& Hernández-Razo, 2014; Martínez-Bolaños, Nieto-Angel, Téliz-Ortiz, Vaquera-Huerta, \& Carrillo Mendoza, 2008). The increasing interest in novel cultivars is due to the great current market competitiveness as well as to the poor adaptation of foreign varieties that have showed higher susceptibility to biotic stress causing serious damage to the strawberry production (Dávalos-González, Narro-Sánchez, Jofre-Garfias, Razo, \& VázquezSánchez, 2009; Dávalos-González et al., 2006; Narro-Sánchez, Dávalos-González, Velásquez-Valle, \& Castro-Franco, 2006). From a commercial perspective, the selection of strawberry genotypes with better adaptation characteristics offers numerous benefits to the producer regions such as a minimization of production costs, and an increase in profitability of the crop and quality of the plant. To date, promising results have been already obtained by applying these advanced crossbreeding selections, which resulted in earlier ripening cultivars more tolerant to agronomical diseases and with higher crop productivity (Dávalos-González et al., 2014). Nevertheless, despite the agronomical potential of new products, their introduction into the market depends on the nutritional and sensory satisfaction of consumers, and generally, this is directly related to their chemical composition. In this sense, deep knowledge related to these aspects are still scarce.

Thus, the aim of this work was to compare the phenolic composition (mainly anthocyanins) of the four strawberry cultivars Nikte, Zamorana, Jacona and Pakal, and to assess the relationships between the chemical composition and the color characteristics of these fruits. Nowadays, the study of color on a scientific basis has been achieved with techniques that allow determining color features that can be associated with the chemical composition of foods. Thus, in this study the colorimetric analysis involved a deep application of Tristimulus Colorimetry by Digital Image Analysis. This technique allows performing a detailed color evaluation on fruits having heterogeneous surface such as strawberries, since the color distribution can be assessed pixel by pixel (every different color within the image can be accounted for one or more pixels).

\section{Materials and methods}

\subsection{Chemicals and reagents}

Chromatographic solvents (acetonitrile and formic acid) were HPLCgrade purchased from Merck (Darmstadt, Germany). All other chemicals (extraction and analytical solvents) were analytical grade and supplied by Panreac Química (Barcelona, Spain). Purified water was obtained from a NANOpure Diamond system (Barnsted Inc.). Standards of ferulic acid ( $\geq 99 \%)$, ellagic acid ( $\geq 95 \%)$, $p$-coumaric acid ( $\geq 98 \%),(+)$-catechin ( $\geq 96 \%)$, quercetin-3-B-O-glucoside ( $\geq 90 \%)$, quercetin $(\geq 95 \%)$ and fisetin $(\geq 98 \%)$ were HPLC-grade purchased from Sigma-Aldrich (Madrid, Spain) while pelargonidin 3-glucoside and cyanidin 3-glucoside ( $\geq 97 \%$ ) from Extrasynthese (Genay, France).

\subsection{Plant material, growing technique and samples}

This study includes fresh strawberries ( $F . x$ ananassa) from four novel Mexican cultivars: Nikte (N), Zamorana (Z), Jacona (J) and Pakal $(\mathrm{P})$. The plants were cultivated in an experimental multitunnel greenhouse with drip irrigation, managed by the Colegio de Posgraduados de Chapingo in Estado de México (latitude $19^{\circ} 27^{\prime} 44.3^{\prime \prime} \mathrm{N}$, longitude $98^{\circ} 54^{\prime} 06.8^{\prime \prime} \mathrm{W}$, Mexico). The climatic conditions of this area were 2220 mamsl (meters above mean sea level), $8.3^{\circ} \mathrm{C}$ as average night temperature about, and $23.0^{\circ} \mathrm{C}$ as average day temperature. The four cultivars were grown in the same field and under the same conditions to minimize the effect of environmental and agronomic factors. The harvesting occurred at commercial ripeness that is when $75 \%$ of the berries' surface showed red color, which corresponds to stage 5 in terms of commercial criterion. At this stage, the selected strawberry samples had the following characteristics: weight $(\mathrm{g})=20.93 \pm 7.83$, Sugars $\left({ }^{\circ} \mathrm{Brix}\right)=$ $7.13 \pm 1.00, \mathrm{pH}=4.78 \pm 0.77$, and titratable acidity (as citric acid) $=$ $0.31 \% .60$ fresh strawberries ( 15 berries per variety) with no apparent physical, insect, or microbial damage were collected, carefully transported to the laboratory, and analyzed separately. All chemical and color analyses were made in technical triplicate.

For digital analysis, images were taken from fresh fruits. Just after taking images, the samples were individually freeze-dried for $24 \mathrm{~h}$ (lyophilizer CRYODOS - 80, Telstar® Varian DS 102) in order to stop the ripening process of strawberry and thus to avoid altering the relations between the color of fruits and their anthocyanic composition.

\subsection{Phenolic extraction}

$100 \mathrm{mg}$ of the homogeneous lyophilized powder of each sample was separately extracted with methanol containing $1 \%$ of concentrated hydrochloric acid, for $12 \mathrm{~h}$, with occasional agitation and sonication, in darkness at room temperature $\left(18-20^{\circ} \mathrm{C}\right)$. Supernatants were centrifuged (4190 g, $5 \mathrm{~min}$ ) and all the methanolic extracts were evaporated to dryness in a rotary evaporator (Eppendorf® Concentrator Plus, Hamburg, Germany), at temperature below $30^{\circ} \mathrm{C}$. In order to remove sugars and polar substances, the residue was dissolved in $2 \mathrm{~mL}$ of ultrapure water and then filtered through an activated Bond Elut C-18 SilicaBased SPE extraction cartridge (Agilent, Palo Alto, CA), washed with water, and the retained phenolic compounds were eluted with $7 \mathrm{~mL}$ of $\mathrm{MeOH}: \mathrm{HCl} 1 \%$. The methanolic extract was concentrated as previously described. The residue was dissolved in $2 \mathrm{~mL}$ of ultrapure water, then centrifuged ( $4190 \mathrm{~g}, 5 \mathrm{~min}$ ) and filtered through a $0.45 \mu \mathrm{m}$ nylon filter (E0034, Análisis Vínicos, Spain).

\subsection{Determination of phenolic compounds by HPLC-DAD-MS analysis}

HPLC-DAD analysis was performed in a Hewlett-Packard 1200 series liquid chromatograph (Palo Alto, CA), equipped with quaternary pump, column heater, UV-vis diode-array detector, automatic injector, and the ChemStation software. The column used was a Zorbax SB C18 
( $4.6 \mathrm{~mm} \times 250 \mathrm{~mm}, 4.6 \mu \mathrm{m}$ particle size) thermostated at $38^{\circ} \mathrm{C}$. All analyses were in triplicate by direct injection of samples.

The chromatographic analysis was a modification of a previously reported method (Heredia et al., 2010) being the solvents (A) acetonitrile/ formic acid/water (3:10:87), and (B) acetonitrile/formic acid/water (50:10:40). The elution profile was as follows: $0-5 \mathrm{~min}, 94 \% \mathrm{~A}$; 5-7.5 min, 70\% A; 7.5-12.5 min, 60\% A; 12.5-16 min, 55\% A; 16-19 $\mathrm{min}, 50 \% \mathrm{~A} ; 19-20 \mathrm{~min}, 94 \% \mathrm{~A}$. The flow rate was $1 \mathrm{~mL} / \mathrm{min}$, and the injected volume was $50 \mu \mathrm{L}$. UV-vis spectra were recorded from 200 to $800 \mathrm{~nm}$ with a bandwidth of $2.0 \mathrm{~nm}$, setting the preferred wavelengths of detection at 280,320,360, and $525 \mathrm{~nm}$.

Identification of non-colored phenolic compounds (low molecular weight) was carried out by comparing their retention times and UVvis spectra with those of original standards previously described. The standard external calibration method was applied for the quantification, using external standards of $p$-coumaric and $(+)$-catechin at $280 \mathrm{~nm}$ for hydroxycinnamic acids and monomeric flavanols (respectively), benzoic acids as ellagic acid at $320 \mathrm{~nm}$, and flavonols as quercetin at $360 \mathrm{~nm}$ (all of them purchased from Sigma-Aldrich, Madrid, Spain). Phenolic compound concentration was expressed as milligrams per $100 \mathrm{~g}$ of strawberry DW. Sums of phenolic acids, monomeric flavan-3ols, and flavonols were also estimated by summing the content of each member identified by HPLC-DAD, respectively.

Anthocyanins were identified by HPLD-DAD-MS and comparison with authentic standards when available. Mass spectrometry was performed using a micrOTOF-QII High Resolution Time-of-Flight mass spectrometer (UHR-TOF) with Q-TOF geometry (Bruker Daltonics, Bremen, Germany) equipped with an electrospray ionization (ESI) interface. The mass spectrometer was connected to the HPLC system via the DAD cell outlet. The instrument operated in positive ion mode $(\mathrm{ESI}+)$ using a scan range from $\mathrm{m} / \mathrm{z} 50-1200$, using Nitrogen as the dry gas at a flow rate of $8 \mathrm{~mL} / \mathrm{min}$ with nebulizing (1.2 bar), and nebulized temperature set at $200{ }^{\circ} \mathrm{C}$. Mass spectra were acquired in MS full scan mode and data were used to perform multitarget-screening using TargetAnalysisTM 1.2 software (Bruker Daltonics, Bremen, Germany), and Bruker Daltonics HyStar 3.2 for instrument control. Anthocyanin compounds were identified by comparing their retention time, UV-vis spectra, and mass spectra features with data reported in the literature. Anthocyanins were quantified from the peak areas recorded at $525 \mathrm{~nm}$ using a standard calibration curve of pelargonidin-3-glucoside (Extrasynthese, Genay, France), and expressing the results as milligrams per $100 \mathrm{~g}$ of strawberry (DW). Total contents of anthocyanins, pelargonidin derivatives and cyanidin derivatives were also estimated by adding the content of each member identified, respectively.

\subsection{Color measurement by Imaging Tristimulus Colorimetry}

Prior to the frozen treatment, the same fresh strawberry fruits considered for the phenolic determination ( $\mathrm{n}=15$ per cultivar) were used to analyze the color by Imaging Tristimulus Colorimetry. The acquisition of images was under homogeneous white LED illumination by using a Canon PowerShot SX500 IS digital camera. In order to minimize the variability between images, all parameters were fixed: flash was disabled, ISO was set at 400 , image size was $4608 \times 3456$ pixels, and shutter speed was set at $1 / 25 \mathrm{~s}$. 3 digitalized images per sample were taken under fixed conditions using a barium sulfate disk as a reference white standard.

Strawberry fruits show heterogeneous surfaces due to the presence of achenes that do not contribute to the anthocyanic composition of the fruit. A segmentation process based on the Imaging Tristimulus Colorimetry allows removing the achenes along the strawberry fruit images. This way, it is possible to consider only the reddish part of the surface in the color measurements. After the image segmentation, a color space transformation from RGB to CIELAB was performed according to the method of Rodríguez-Pulido, Gordillo, González-Miret, and Heredia (2013), with the software MATLAB. The CIELAB color parameters obtained $\left(\mathrm{L}^{*}, \mathrm{a}^{*}, \mathrm{~b}^{*}, \mathrm{C}^{*}{ }_{\mathrm{ab}}\right.$, and $\left.\mathrm{h}_{\mathrm{ab}}\right)$ were averages of three measurements. In addition, the Euclidean distance between two points in the three-dimensional space defined by $\mathrm{L}^{*}, \mathrm{a}^{*}$, and $\mathrm{b}^{*}$ was used to calculate the color difference between samples as follows: $\Delta \mathrm{E}^{*}{ }_{\mathrm{ab}}=$ $\left[\left(\Delta \mathrm{L}^{*}\right)^{2}+\left(\Delta \mathrm{a}^{*}\right)^{2}+\left(\Delta \mathrm{b}^{*}\right)^{2}\right]^{1 / 2}$.

\subsection{Statistical analysis}

All statistical analyses were performed using Statistica v.8.0 software (StatSoft. Inc., 2007). Analysis of variance (ANOVA, Tukey test) and forward Linear Discriminant Analysis (LDA) were applied in order to evaluate whether significant differences $(p<0.05)$ among the strawberry cultivars existed as well as to select the variable that most influence these differences.

\section{Results and discussion}

\subsection{Phenolic composition of strawberry cultivars}

Up to 24 phenolic compounds were identified and quantified belonging to four different groups (Fig. 1): (a) phenolic acids ( $p$-coumaric acid, ellagic acid, one ferulic acid derivative and two $p$-coumaric acid derivatives), (b) monomeric flavanols ((+)-catechin), (c) flavonols (quercetin 3-O-glucoside, fisetin and one quercetin 3-O-glucoside derivative), and (d) anthocyanins (cyanidin 3-glucoside, cyanidin 3-rutinoside, cyanidin pentoside, pelargonidin 3-galactoside, pelargonidin 3,5-diglucoside, pelargonidin 3-glucoside, pelargonidin 3-rutinoside, cyanidin 3-Oacetylglucoside, cyanidin hexoside, pelargonidin 3-O-monoglucuronide, and four pelargonidin derivatives). Table 1 shows the concentrations and the mean values of the identified individual phenolic compounds (mg/100 g DW). Specifically, anthocyanin compounds were accurately identified by HPLC-DAD-MS analysis at $525 \mathrm{~nm}$ from suitable information concerning their UV-vis or mass spectral characteristics (Table 2), and comparing with those reported by relevant literature references (Aaby et al., 2012; Carazzone, Mascherpa, Gazzani, \& Papetti, 2013; Holzwarth et al., 2012; Lopes da Silva et al., 2007; Sun, Liu, Yang, Slovin, \& Chen, 2014).

The phenolic profile of the four strawberry varieties was apparently quite similar in qualitative terms but significant $(p<0.05)$ quantitative differences were found for most of the individual compounds identified. Considering total phenolic content as the sum of the all phenolics identified, the average value varied from 481.26 to $989.60 \mathrm{mg} / 100 \mathrm{~g} \mathrm{DW}$, with anthocyanins comprising the majority of these compounds and flavonols the minority, being in accordance with previous studies (Aaby et al., 2012; Hernanz et al., 2007). Considering each phenolic family, Zamorana and Nikte cultivars had the highest average levels of anthocyanins ( 772.1 and $736.9 \mathrm{mg} / 100 \mathrm{~g}$ DW, respectively). Nevertheless, these two varieties were different according to their contents in phenolic acids and flavanols. In this sense cv. Zamorana showed significantly higher amounts of phenolic acids while cv. Nikte was richer in flavanols ( 198.5 versus $103.3 \mathrm{mg} / 100 \mathrm{~g}$ DW and 66.5 versus 17.8 $\mathrm{mg} / 100 \mathrm{~g}$ DW, respectively). On contrast cv. Pakal showed the lowest content of anthocyanins compared to the other varieties (222.7 $\mathrm{mg} / 100 \mathrm{~g} \mathrm{DW})$, which seems to be compensated with a significant higher production of phenolic acids ( $233.9 \mathrm{mg} / 100 \mathrm{~g}$ DW). Since all the strawberry cultivars studied were grown under the same conditions and harvested at the same maturity level, these chemical differences can be specific varietal characteristics (Lopes da Silva et al., 2007). Manipulation of these strawberry genotypes achieved by natural selection was mainly oriented to obtain higher fruit production or climate and plague resistance (Martínez-Bolaños et al., 2008; Dávalos-González et al., 2009). This genetic manipulation also induces differences in the content of specific compounds with biological and sensory importance, which has been observed in this study. In general terms, the global content on anthocyanins of the new strawberry cultivars were similar (cv. Pakal) or even 


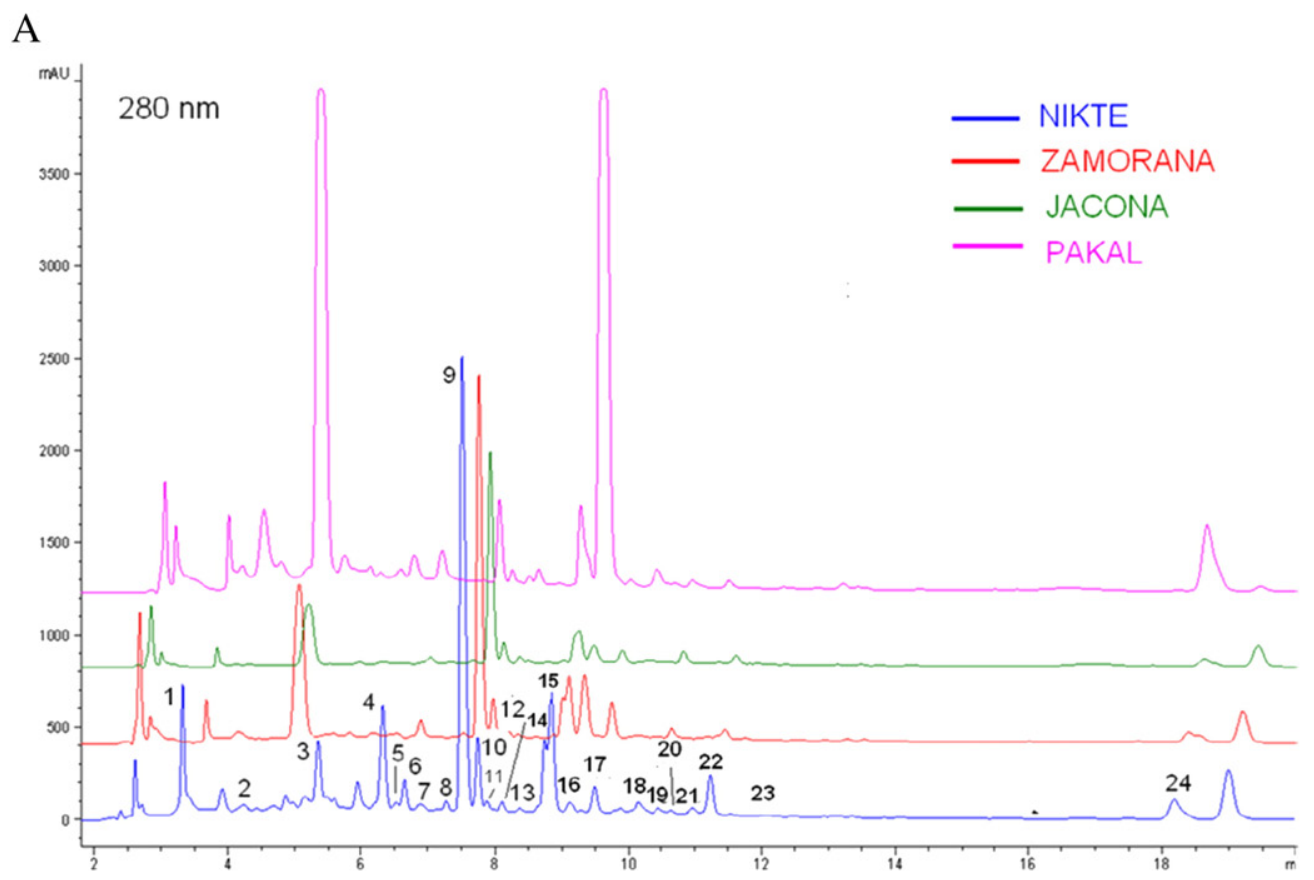

B

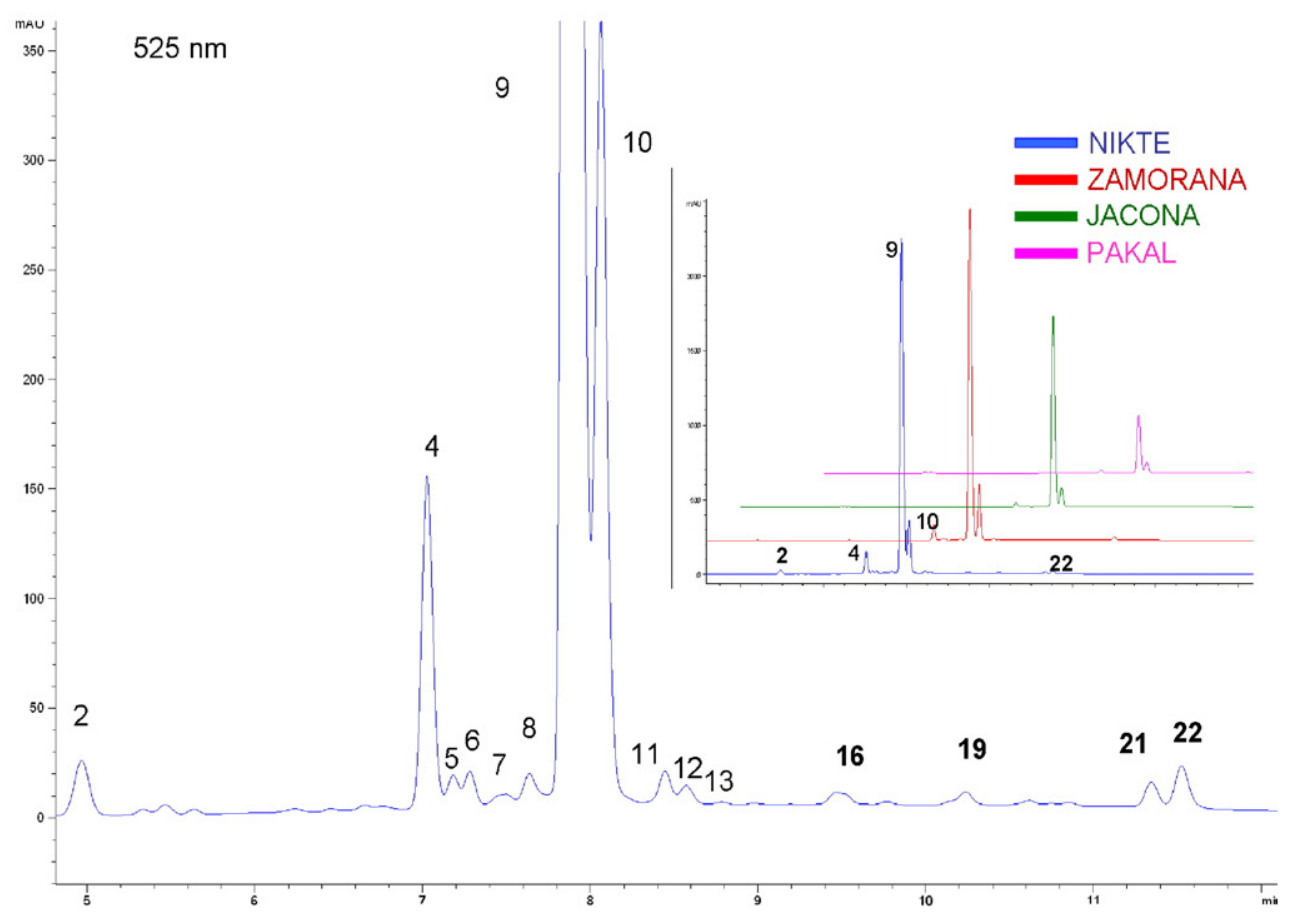

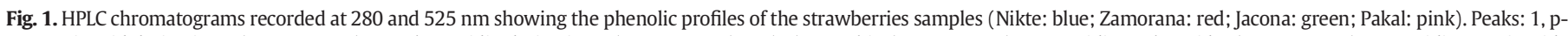

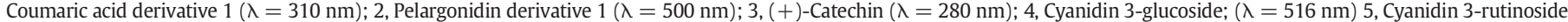

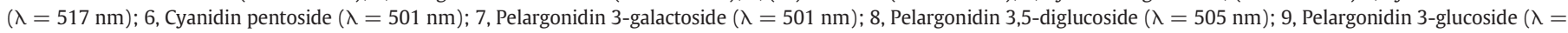

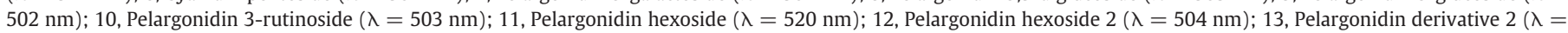

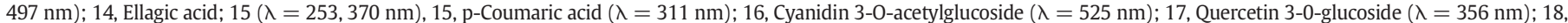

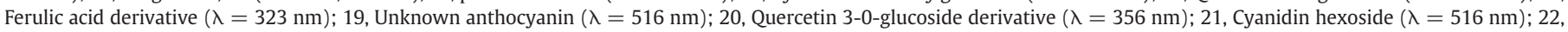
Pelargonidin 3-O-monoglucuronide $(\lambda=514 \mathrm{~nm}) ; 24$, Fisetin $(\lambda=360 \mathrm{~nm}) ; 25$, p-Coumaric acid derivative $2(\lambda=310 \mathrm{~nm})$.

higher (cv. Nikte, Zamorana and Jacona) than the contents described by Basu et al. (2014) for other commercial strawberry cultivars such as Elsanta and Kent. Nevertheless, it is important to take into account that the strawberry composition can be conditioned by other climatic, environmental or agronomic factors so a high variability in the content of different bioactive compounds can occur (Hernanz et al., 2008).

Taking into consideration only the group of anthocyanin pigments, 15 compounds were detected in samples mainly identified as pelargonidin and cyanidin derivatives (Fig. 1B). Concerning the relative 
Concentrations ( $\mathrm{mg} / 100 \mathrm{~g}$ DW; mean values $\pm \mathrm{SD}, \mathrm{n}=15$ ) of the phenolic compounds and CIELAB color parameters ( $\mathrm{n}=300$ pixels/sample) of the strawberry cultivars studied.

\begin{tabular}{|c|c|c|c|c|}
\hline & \multicolumn{4}{|l|}{ Strawberry cultivar ${ }^{a}$} \\
\hline & $\mathrm{N}$ & Z & $\mathrm{J}$ & $\mathrm{P}$ \\
\hline Total phenolics ${ }^{\mathrm{b}}$ & $910.01 \pm 181.23 \mathrm{a}$ & $989.65 \pm 155.56 b$ & $668.70 \pm 134.32 c$ & $481.26 \pm 38.23 \mathrm{~d}$ \\
\hline Sum of anthocyanins & $736.98 \pm 178.09 a$ & $772.01 \pm 204.87 \mathrm{a}$ & $494.93 \pm 127.58 b$ & $222.75 \pm 28.34 \mathrm{c}$ \\
\hline Sum of pelargonidin derivatives & $662.21 \pm 174.65 \mathrm{a}$ & $706.10 \pm 200.5 \mathrm{a}$ & $439.52 \pm 94.67 \mathrm{~b}$ & $175.49 \pm 27.48 c$ \\
\hline Sum of cyanidin derivatives & $66.18 \pm 7.54 \mathrm{a}$ & $55.82 \pm 6.9 \mathrm{~b}$ & $47.73 \pm 3.53 c$ & $35.89 \pm 3.49 \mathrm{~d}$ \\
\hline Sum of phenolic acids & $103.33 \pm 7.24 \mathrm{a}$ & $198.51 \pm 71.09 b$ & $158.63 \pm 44.10 \mathrm{c}$ & $233.92 \pm 24.41 \mathrm{~d}$ \\
\hline Sum of monomeric flavan-3-ols & $66.54 \pm 23.22 \mathrm{a}$ & $17.78 \pm 3.23 \mathrm{~b}$ & $12.20 \pm 5.87 \mathrm{~b}$ & $21.45 \pm 5.27 \mathrm{~b}$ \\
\hline Sum of flavonols & $3.16 \pm 0.52 \mathrm{a}$ & $1.35 \pm 0.34 \mathrm{~b}$ & $2.94 \pm 0.18 \mathrm{a}$ & $3.14 \pm 1.96 \mathrm{a}$ \\
\hline \multicolumn{5}{|l|}{ Phenolic compounds } \\
\hline \multicolumn{5}{|l|}{ Antocyanins } \\
\hline Pelargonidin derivative 1 & $11.46 \pm 1.25 \mathrm{a}$ & $5.70 \pm 4.75 b$ & tr. & n.d. \\
\hline Cyanidin 3-glucoside & $27.37 \pm 5.00 a$ & $26.47 \pm 3.72 \mathrm{a}$ & $18.66 \pm 3.22 b$ & $16.33 \pm 3.30 b$ \\
\hline Cyanidin 3-rutinoside & $11.45 \pm 0.42 \mathrm{a}$ & $10.68 \pm 0.75 b$ & $9.90 \pm 0.33 c$ & $9.94 \pm 0.48 c$ \\
\hline Cyanidin pentoside & $10.88 \pm 0.75 a$ & $9.29 \pm 3.25 b$ & $9.83 \pm 0.62 \mathrm{ab}$ & n.d \\
\hline Pelargonidin 3-galactoside & $10.44 \pm 0.60 \mathrm{a}$ & $9.96 \pm 0.46 \mathrm{ab}$ & $9.41 \pm 0.19 b c$ & $8.57 \pm 2.82 \mathrm{cc}$ \\
\hline Pelargonidin 3,5-diglucoside & $11.62 \pm 0.80 \mathrm{a}$ & $11.76 \pm 0.87 a$ & $10.27 \pm 0.40 b$ & $9.52 \pm 0.33 c$ \\
\hline Pelargonidin 3-glucoside & $522.98 \pm 169.47 \mathrm{a}$ & $568.28 \pm 174.46 \mathrm{a}$ & $335.08 \pm 113.12 b$ & $93.74 \pm 22.18 c$ \\
\hline Pelargonidin 3-rutinoside & $71.49 \pm 8.77 \mathrm{a}$ & $66.55 \pm 19.17 \mathrm{a}$ & $52.22 \pm 9.36 \mathrm{~b}$ & $23.72 \pm 2.89 \mathrm{c}$ \\
\hline Pelargonidin hexoside 1 & n.d. & $9.05 \pm 3.15 \mathrm{a}$ & $2.33 \pm 4.09 \mathrm{~b}$ & $9.94 \pm 0.84 \mathrm{a}$ \\
\hline Pelargonidin hexoside 2 & $12.08 \pm 0.77 \mathrm{a}$ & $10.67 \pm 0.65 b$ & $10.05 \pm 0.38 c$ & $9.81 \pm 0.47 c$ \\
\hline Pelargonidin derivative 2 & $8.58 \pm 4.19 \mathrm{a}$ & $10.73 \pm 0.84 b$ & $9.42 \pm 2.91 \mathrm{ab}$ & $9.51 \pm 1.80 \mathrm{a}$ \\
\hline Cyanidin 3-O-acetylglucoside & $8.07 \pm 3.97 \mathrm{a}$ & $9.37 \pm 0.52 \mathrm{ab}$ & $9.35 \pm 0.50 \mathrm{~b}$ & $9.64 \pm 0.31 b$ \\
\hline Unknown anthocyanin & $8.60 \pm 3.70 \mathrm{a}$ & $10.09 \pm 0.47 b$ & $7.74 \pm 0.44 \mathrm{ab}$ & $11.34 \pm 0.80 \mathrm{c}$ \\
\hline Cyanidin hexoside & $8.42 \pm 3.61 \mathrm{a}$ & n.d. & n.d & n.d \\
\hline Pelargonidin 3-O-monoglucuronide & $13.56 \pm 1.53 \mathrm{a}$ & $13.41 \pm 2.77 \mathrm{a}$ & $10.74 \pm 0.87 \mathrm{~b}$ & $10.69 \pm 1.11 \mathrm{~b}$ \\
\hline \multicolumn{5}{|l|}{ Phenolic acids } \\
\hline$p$-Coumaric acid derivative 1 & $14.32 \pm 0.31 \mathrm{a}$ & $26.34 \pm 8.25 b$ & $20.63 \pm 3.22 c$ & $59.20 \pm 15.36 \mathrm{~d}$ \\
\hline p-Coumaric acid & $15.68 \pm 0.49 a$ & $79.54 \pm 44.50 \mathrm{~b}$ & $50.60 \pm 26.21 c$ & $54.12 \pm 6.59 c$ \\
\hline Ferulic acid derivative & $17.22 \pm 0.85 \mathrm{a}$ & $15.75 \pm 0.71 \mathrm{~b}$ & $15.18 \pm 0.62 c$ & $19.01 \pm 1.26 \mathrm{~d}$ \\
\hline Ellagic acid & $13.89 \pm 3.15 \mathrm{a}$ & $27.35 \pm 13.83 \mathrm{~b}$ & $29.5 \pm 12.71 \mathrm{~b}$ & $29.58 \pm 5.92 b$ \\
\hline p-Coumaric acid derivative 2 & $42.22 \pm 6.34 \mathrm{a}$ & $49.52 \pm 19.41 \mathrm{a}$ & $42.64 \pm 11.36 \mathrm{a}$ & $72.02 \pm 12.00 \mathrm{~b}$ \\
\hline \multicolumn{5}{|l|}{ Monomeric flavanols } \\
\hline$(+)$-Catechin & $66.54 \pm 23.22 \mathrm{a}$ & $17.78 \pm 3.23 b$ & $12.20 \pm 5.87 b$ & $21.45 \pm 5.27 b$ \\
\hline \multicolumn{5}{|l|}{ Flavonols } \\
\hline Quercetin 3-0-glucoside & $1.31 \pm 0.14 \mathrm{a}$ & $1.27 \pm 0.10 \mathrm{a}$ & $1.19 \pm 0.07 \mathrm{~b}$ & $1.16 \pm 0.04 b$ \\
\hline Quercetin 3-0-glucoside derivative & $1.85 \pm 0.54 \mathrm{a}$ & tr. & $1.75 \pm 0.13 \mathrm{a}$ & $1.17 \pm 0.10 b$ \\
\hline Fisetin & n.d. & n.d & n.d. & tr. \\
\hline \multicolumn{5}{|l|}{ Color data } \\
\hline $\mathrm{L}^{*}$ & $38.77 \pm 5.43 a$ & $39.54 \pm 7.36 \mathrm{a}$ & $40.95 \pm 7.51 b$ & $42.03 \pm 6.95 b$ \\
\hline$a^{*}$ & $50.16 \pm 4.74 \mathrm{a}$ & $49.32 \pm 5.48 \mathrm{a}$ & $49.27 \pm 5.35 a$ & $52.42 \pm 4.94 b$ \\
\hline$b^{*}$ & $31.99 \pm 7.13 \mathrm{a}$ & $32.87 \pm 9.37 \mathrm{a}$ & $35.63 \pm 8.69 b$ & $39.43 \pm 7.69 c$ \\
\hline $\mathrm{C}^{*}{ }_{\mathrm{ab}}$ & $59.83 \pm 6.58 \mathrm{a}$ & $59.82 \pm 8.35 a$ & $61.30 \pm 7.85 b$ & $65.89 \pm 7.34 c$ \\
\hline $\mathrm{h}_{\mathrm{ab}}$ & $32.02 \pm 5.78 \mathrm{a}$ & $32.88 \pm 6.90 \mathrm{a}$ & $35.25 \pm 6.32 b$ & $36.56 \pm 5.00 \mathrm{~b}$ \\
\hline
\end{tabular}

Different letters in the same row mean significant differences (Tukey test, $p<0.05$ ) between strawberry cultivarstr.: traces; n.d.: no detected.

a N (Nikte), Z (Zamorana), J (Jacona), P (Pakal).

b As sum of all phenolics identified.

proportion of these two groups of anthocyanins, some differences were observed among the cultivars (Table 1). While Nikte, Zamorana and Jacona showed similar proportions of pelargonidin/cyanidin derivatives
( $90 \%$ versus $10 \%$, respectively), Pakal was noteworthy for having much higher proportion of cyanidin derivatives (78\% versus 16\%). Notwithstanding, in agreement with previous reports about other strawberry

Table 2

Retention times, mass spectra details and chromatographic UV-vis spectral data of anthocyanins found in the strawberry cultivars by HPLC-DAD-MS analysis.

\begin{tabular}{|c|c|c|c|c|c|c|c|c|c|}
\hline \multirow[t]{2}{*}{ Peak } & \multirow[t]{2}{*}{ Rt (min) } & \multirow[t]{2}{*}{$\lambda_{\max }(\mathrm{nm})$} & \multirow[t]{2}{*}{$\mathrm{MS}^{+}(\mathrm{m} / \mathrm{z})$} & \multirow[t]{2}{*}{$\mathrm{MS}^{2}$ frag. } & \multirow[t]{2}{*}{ Tentative identification } & \multicolumn{4}{|c|}{ Strawberry cultivar ${ }^{a}$} \\
\hline & & & & & & $\mathrm{N}$ & $\mathrm{Z}$ & $\mathrm{J}$ & $\bar{P}$ \\
\hline 2 & 4.9 & 500 & 595 & 405,271 & Pelargonidin derivative 1 & $*$ & $*$ & $\operatorname{tr}$ & nd \\
\hline 4 & 7.0 & 516 & 449 & 287 & Cyanidin 3-glucoside & $*$ & $*$ & $*$ & $*$ \\
\hline 5 & 7.2 & 515 & 595 & 449,287 & Cyanidin 3-rutinoside & $*$ & $*$ & $*$ & $*$ \\
\hline 6 & 7.3 & 501 & 419 & 287 & Cyanidin-pentoside & $*$ & $*$ & $*$ & nd \\
\hline 7 & 7.5 & 501 & 433 & 271 & Pelargonidin 3-galactoside & $*$ & $*$ & $*$ & $*$ \\
\hline 8 & 7.6 & 505 & 595 & 433,271 & Pelargonidin 3,5-diglucoside & $*$ & * & $*$ & $*$ \\
\hline 9 & 7.8 & 502 & 433 & 271 & Pelargonidin 3-glucoside & * & * & $*$ & * \\
\hline 10 & 8.1 & 503 & 579 & 433,271 & Pelargonidin 3-rutinoside & $*$ & $*$ & $*$ & $*$ \\
\hline 11 & 8.2 & 520 & 433 & 271 & Pelargonidin hexoside 1 & nd & * & $*$ & $*$ \\
\hline 12 & 8.5 & 504 & $765 / 433$ & 271 & Pelargonidin hexoside 2 & $*$ & $*$ & $*$ & $*$ \\
\hline 13 & 8.6 & 497 & $501 / 433$ & 309,271 & Pelargonidin derivative 2 & $*$ & $*$ & $*$ & $*$ \\
\hline 15 & 9.7 & 525 & 491 & 287 & Cyanidin 3-O-acetylglucoside & * & $*$ & $*$ & * \\
\hline 18 & 10.2 & 516 & 422 & 331 & Unknown anthocyanin & * & * & $*$ & * \\
\hline 20 & 11.3 & 516 & 449 & 287 & Cyanidin hexoside & $*$ & nd & nd & nd \\
\hline 21 & 11.6 & 514 & 447 & 271 & Pelargonidin 3-O-monoglucuronide & $*$ & $*$ & $*$ & $*$ \\
\hline
\end{tabular}

tr.: traces; n.d.: not detected.

${ }^{a} \mathrm{~N}$ (Nikte), Z (Zamorana), J (Jacona), P (Pakal). 
varieties (Hernanz et al., 2007) the major anthocyanins in all samples corresponded to cyanidin-3-glucoside ( $\mathrm{m} / \mathrm{z}$ 449, $\mathrm{MS}^{2}$ 287), pelargonidin-3-glucoside ( $\left.\mathrm{m} / \mathrm{z} 433, \mathrm{MS}^{2} 271\right)$, and pelargonidin-3rutinoside ( $\mathrm{m} / \mathrm{z} 579, \mathrm{MS}^{2} 433 / 271$ ), as shown in Table 2 . Their identities were easily identified by UV-vis and MS analysis, providing a very high response factor. These anthocyanins were present in samples in considerably higher concentrations accounting for $85 \%, 84 \%, 82 \%$ and $60 \%$ of the total anthocyanin content in Zamorana, Nikte, Jacona and Pakal cultivars, respectively. Considering the average values, the main anthocyanin was pelargonidin 3-glucoside, with mean levels 1.5-fold higher in Zamorana and Nikte cultivars than in Jacona and 6-fold higher than Pakal. These data lead to conclude that the genetic differences between the novel strawberry cultivars studied accounted for large differences not only in the global pigment content of their fruits but also in the individual anthocyanin compounds. In this context, Nikte and Zamorana cultivars are more similar to each other, slightly different from cv. Jacona and quite different from cv. Pakal. On the other hand, cv. Zamorana is similar to cv. Jacona but also quite richer in anthocyanins than cv. Pakal.

Although some of these compounds were recognized as pelargonidin or cyanidin glycoside derivatives, the identity of the sugar to which they are conjugated remained unknown or tentatively identified (Table 2). Therefore, their structures still need to be elucidated by comparison of MS data with reference standards or using other spectroscopic techniques such as NMR. These are the cases of a cyanindin pentoside ( $\mathrm{m} / \mathrm{z} 419, \mathrm{MS}^{2} 287$ ), which was present in all varieties except for cv. Pakal, or a cyanidin hexoside ( $\mathrm{m} / \mathrm{z} 449, \mathrm{MS}^{2} 287$ ), which was only present in cv. Nikte.

As reported in literature, anthocyanins are the phenolics that have received most attention in strawberry; they are directly responsible for the bright red color of the berries, and contribute to demonstrated health benefits (Basu et al., 2014). Thus, differences on the concentration and composition of anthocyanins between cultivars could be important for the sensory and biological value of fruits and products.

Other non-colored individual phenolics were also comparatively assessed for strengthening the characterization of the studied strawberry cultivars, showing significant differences for most of the identified compounds (Table 1). Thus, high phenolic acid content stands out in these strawberry cultivars, mainly $p$-coumaric acid and ellagic acid, finding the highest amounts in cv. Pakal (59.20 and $29.58 \mathrm{mg} / 100 \mathrm{~g}$ DW, respectively). The $(+)$-catechin content stands out in cv. Nikte (66.5 mg/100 g DW), showing mean levels almost 3-fold higher than in the other cultivars. Although some flavonols such as fisetin are minor phenolics found in some cases only in traces, they have remarkable health benefits, and hence nutritional importance (Prasath \& Subramanian, 2014).

\subsection{Color of strawberry cultivars by Imaging Tristimulus Colorimetry}

The assessment of color by Imaging Tristimulus Colorimetry successfully evaluated the reddish surface of strawberries. This measurement allows removing the achenes that affect the overall appearance but do not contribute to the anthocyanic composition of the fruit. This selective measurement was possible thanks to the segmentation process (Rodríguez-Pulido et al., 2013), which cannot be performed by conventional colorimetric instruments such as spectroradiometers or colorimeters.

The upper-left corner in Fig. 2 shows the segmentation mask, which marks in white the area considered for the color measurement. The corresponding CIELAB color parameters $\left(\mathrm{L}^{*}, \mathrm{a}^{*}, \mathrm{~b}^{*}, \mathrm{C}^{*}{ }_{\mathrm{ab}}\right.$ and $\mathrm{h}_{\mathrm{ab}}$ ) are summarized in Table 1 . Pakal had the highest lightness value $\left(\mathrm{L}^{*}\right)$, followed by Jacona, Zamorana and Nikte, and the same order was found for chroma $\left(\mathrm{C}^{*} \mathrm{ab}\right)$ and hue $\left(\mathrm{h}_{\mathrm{ab}}\right)$ values. Pakal was quite different from all the rest, while Nikte and Zamorana were the more similar varieties. The differences of the individual CIELAB color parameters were significant $(p<0.05)$ in virtually all cases. Graphically, this can be appreciated in Fig. 2, which shows the location of the color distribution on the CIELAB color space ( $\mathrm{a}^{*} \mathrm{~b}^{*}$-diagram and lightness), comparing $\mathrm{cv}$. Pakal with the other varieties: Pakal-Nikte (Fig. 2A), Pakal-Jacona (Fig. 2B), and Pakal-Zamorana (Fig. 2C). The distribution of the samples in the $\left(\mathrm{a}^{*} \mathrm{~b}^{*}\right)$ plane indicate that there is a more clear separation between the color of Pakal respect to Nikte and Zamorana than to Jacona fruits.

In order to establish whether the observed changes in the CIELAB parameters were visually relevant, the CIELAB color difference $\left(\Delta E^{*}{ }_{a b}\right)$ was assessed comparing varieties by pairs. Also, in an attempt to understand the significance of the color changes, the absolute lightness, chroma, and hue differences $\left(\Delta \mathrm{L}^{*}, \Delta \mathrm{C}^{*} \mathrm{ab}\right.$, and $\left.\Delta \mathrm{h}_{\mathrm{ab}}\right)$ were calculated.

According to Martínez, Melgosa, Pérez, Hita, and Negueruela (2001), $\Delta \mathrm{E}^{*}$ ab around 3 units indicates, approximately, color differences appreciable to the human eyes (as an average observer). Based on this premise, results showed that Pakal cv. can be visually differentiated from the other strawberry cultivars in colorimetric terms, since all pairs of $\Delta \mathrm{E}^{*}{ }_{\mathrm{ab}}$ were higher than 3.0 units. Specifically, Nikte and Pakal (N-P) showed the highest color difference $\left(\Delta \mathrm{E}_{\mathrm{ab}}^{*}=8.43\right.$ units) and therefore, the most perceptible color changes. On the other hand, Nikte and Zamorana $(\mathrm{N}-\mathrm{Z})$ showed the lowest color difference $\left(\Delta \mathrm{E}_{\mathrm{ab}}^{*}=1.43\right.$ units), which can be considered negligible.

Regarding individual color components (lightness $\mathrm{L}^{*}$, chroma $\mathrm{C}_{\mathrm{ab}}^{*}$ and hue $\mathrm{h}_{\mathrm{ab}}$ ), the corresponding differences ranged from $3.3 \mathrm{u}$. (N-P) to $0.7 \mathrm{u}$. (N-Z) for $\Delta \mathrm{L}^{*}$, from $6.1 \mathrm{u}$. $(\mathrm{N}-\mathrm{P})$ to $0.0 \mathrm{u}$. $(\mathrm{N}-\mathrm{Z})$ for $\Delta \mathrm{C}^{*}$ ab , and from $4.5 \mathrm{u}$. (N-P) to $0.8 \mathrm{u}$. $(\mathrm{N}-\mathrm{Z})$ in the case of $\Delta \mathrm{h}_{\mathrm{ab}}$. These three components of color can contribute in different proportions to the global color difference, that is, the differences in color between samples can be due to dissimilarities in these three attributes. In order to know the percentages of contribution on the color difference among the varieties of strawberries by pairs, a study of every component in percentage $\left(\% \Delta^{2} \mathrm{~L}, \% \Delta^{2} \mathrm{C}\right.$ and $\% \Delta^{2} \mathrm{H}$ ) was carried out, which is shown in Fig. 3 . It is noticeable that the color difference between cv. Pakal and all the other varieties is mainly due to the chroma contribution, especially in the case of cv. Jacona. Color differences for cv. Jacona with Nikte and Zamorana cultivars were also due to dissimilarities in hue, that is, the qualitative attribute of color. As previously commented, these colorimetric results are consequences of the variability of the anthocyanin composition of each variety and are in agreement with the color distribution of samples in the ( $\left.\mathrm{a}^{*} \mathrm{~b}^{*}\right)$ plane (Fig. 2 ).

The chemical composition (mainly pigments) deeply affects the color characteristics of fruits (Hernanz, Recamales, Meléndezmartínez, González-miret, \& Heredia, 2008). The appearance of any pigment involves light absorption phenomena that induce changes in the values of the color parameters. Thus, the highest $\mathrm{L}^{*}$ values of $\mathrm{cv}$. Pakal are in agreement with its lowest anthocyanin content (the higher pigment content the higher light absorption, and so a decrease of lightness occurs). In the same way, the anthocyanin content of cv. Jacona was below Nikte and Zamorana varieties and above cv. Pakal, which resulted in proportional color-composition increments.

The differences in hue values $\left(\mathrm{h}_{\mathrm{ab}}\right)$ are usually consequences of qualitative differences in the chemical profiles since pelargonidin gives a more defined orange hue than cyanidin.

When the anthocyanin profiles are different also the chroma $\left(\mathrm{C}^{*}{ }_{\mathrm{ab}}\right)$ can be affected. Thus, Nikte, Zamorana and Jacona cultivars showed a $90 \%$ higher proportion of pelargonidin than cyanidin and this amount was lower in cv. Pakal. Accordingly, chroma values were around 60.0 CIELAB units for all varieties, slightly higher (mean value 66 CIELAB units) for cv. Pakal. Hence, this could mean that cyanidin provides a more vivid color than pelargonidin.

\subsection{Linear discriminant analysis (LDA)}

By comparing the four groups of samples based on their phenolic composition and colorimetric characteristics, a linear discriminant analysis (LDA) was performed to examine the ability of the variables 
A
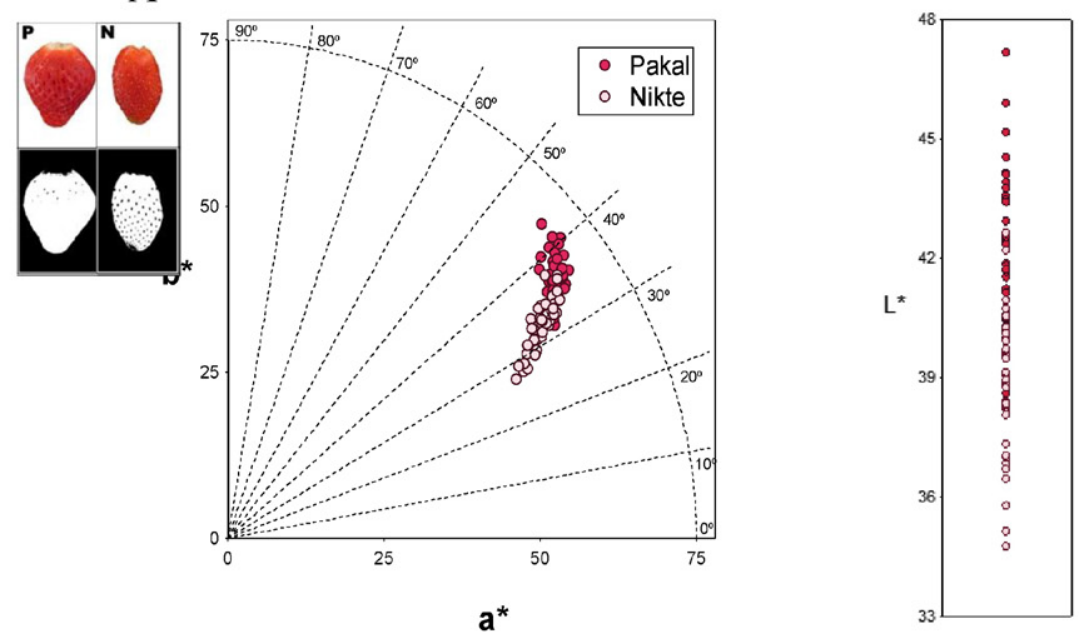

B
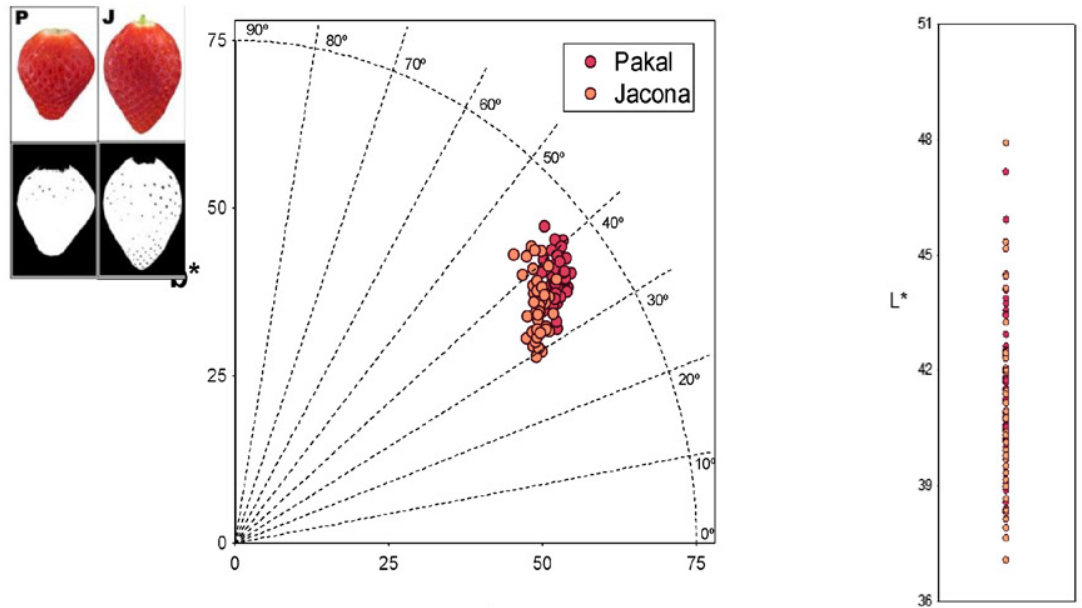

$a^{*}$

$\mathrm{C}$
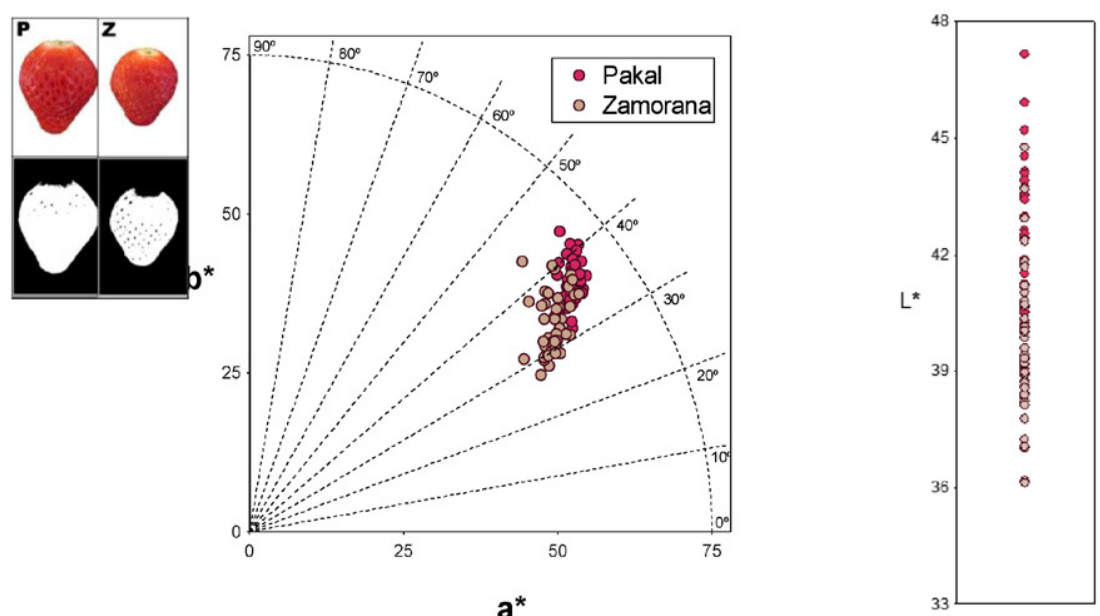

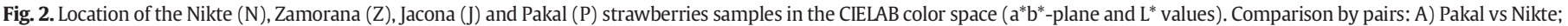
B) Pakal vs Jacona, and C) Pakal vs Zamorana. ( $\mathrm{n}=15$ samples/variety; for color data $\mathrm{n}=300$ point/sample). Images of the spectral treatment are shown.

obtained to differentiate among strawberry cultivars. A forward stepwise method, which includes variables step-by-step, beginning with the more significant until no significant changes were chosen in this work.
Concretely, the individual phenolic compounds (monomeric anthocyanins, phenolic acids and their derivatives, flavan-3-ols and flavonols) and the angular coordinates of the CIELAB space $\left(\mathrm{L}^{*} \mathrm{C}^{*}{ }_{\mathrm{ab}}\right.$ and $\left.\mathrm{h}_{\mathrm{ab}}\right)$ were used as discriminant variables. The rest of the color variables were not 


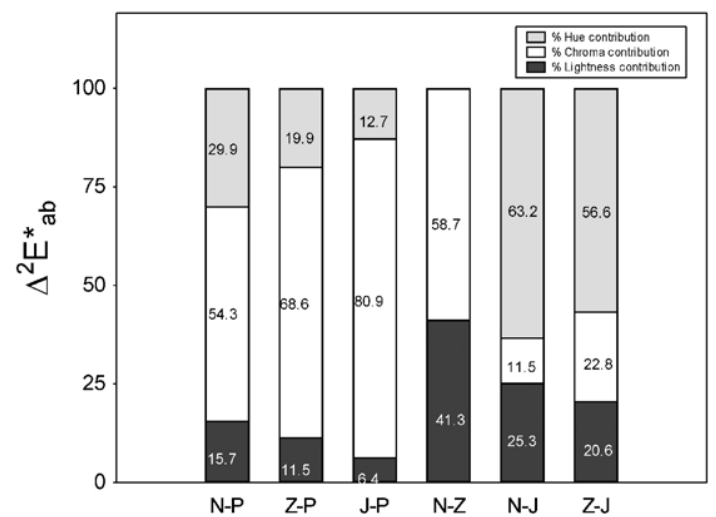

Fig. 3. Relative contribution of lightness $\left(\% \Delta^{2} \mathrm{~L}\right)$, chroma $\left(\% \Delta^{2} \mathrm{C}\right)$, and hue $\left(\% \Delta^{2} \mathrm{H}\right)$ to the total color difference $\left(\Delta^{2} \mathrm{E}_{\mathrm{ab}}^{*}\right)$ calculated for each pair of strawberry varieties (Nikte: $\mathrm{N}$, Zamorana: Z, Jacona: J, and Pakal: P).

included in the LDA in order to avoid redundant information. The criterion for the selection was Wilks's $\lambda$, which maximizes the ratio of variance between groups to that within groups. A $F$ statistic is computed from the partial $\lambda$ values, leading to a $p$ level. The maximum discriminatory power corresponds to minimum $p$ level values.

A mathematical model that selected 8 of the 27 variables included in the statistical analysis and classified correctly $95 \%$ of the cases with high levels of significance $(p<0.001)$ was obtained. These variables were 5 anthocyanins (cyanidin 3-glucoside, pelargonidin 3-glucoside, pelargonidin 3-rutinoside, pelargonidin hexoside 2, and cyanidin hexoside) and three colorless phenolics belonging to phenolic acids and flavonol families (Quercetin 3-0-glucoside derivative, $p$-coumaric acid derivative 1 , and ferulic acid derivative). Additionally, it was seen that the prediction percentages were $100 \%$ for all strawberry cultivars when the mathematical model included 13 variables. In this case, despite three additional phenolic compounds (pelargonidin derivative 2 , cyanidin 3-O-acetylglucoside, and quercetin 3-0-glucoside), the color parameter lightness $\left(\mathrm{L}^{*}\right)$ and chroma $\left(\mathrm{C}^{*}{ }_{\mathrm{ab}}\right)$ were considered as discriminant functions. This fact means that the colorimetric characteristics had a significant role in the differentiation of strawberry fruits according to the cultivar, especially the quantitative attributes.

The location of the strawberry samples within the plane defined by the two corresponding canonical functions is showed in Fig. 4. The scatterplot shows a quite good separation among the samples as a function of the cultivar. It can be observed that the first function allowed the samples to be classified into two groups, one of them including the

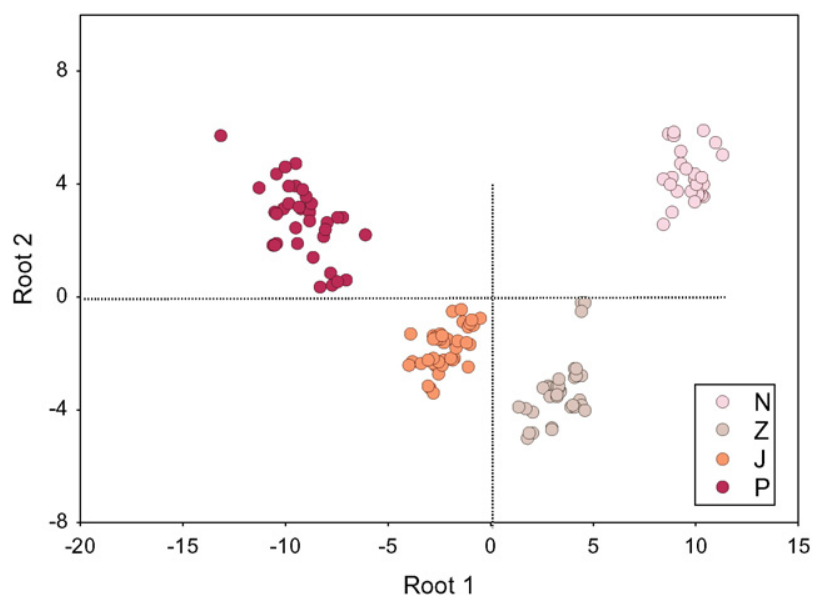

Fig. 4. Scatterplot of the canonical scores from LDA based on the phenolic composition and color data of novel strawberry cultivars studied (Nikte: N, Zamorana: Z, Jacona: J, and Pakal: P). samples from the varieties Zamorana and Nikte (with higher contents of pelargonidin 3-glucoside and pelargonidin 3-rutinosde) and the other including Jacona and Pakal (with higher values of lightness and chroma). The second canonical function was mainly linked to the levels of ferulic acid derivative, which take positive sign for Nikte and Pakal cultivars located (highest levels of this compound).

\section{Conclusions}

This work provides a better knowledge about the nutritional and sensory quality of novel strawberry cultivars (Nikte, Zamorana Jacona and Pakal), especially in terms of their antioxidant content (mainly anthocyanins) and color characteristics. Imaging Tristimulus Colorimetry has demonstrated to be a useful analytical tool to improve the evaluation of color in heretogenous samples as strawberry fruits, so the relationship between the color and anthocyanin composition was evaluated in a comprehensive manner. Multivariate statistical techniques (Linear Discriminant Analysis) revealed significant differences between major and minor phenolic compounds among cultivars due to specific genotypic features, which affect their appearance properties. Such differences were in terms of higher total anthocyanin content and the darkest color of fruits for Nikte and Zamorana cultivars, followed by Jacona. cv. Pakal exhibited the lighter but more vivid color and higher relative proportion of cyanidin derivatives. Although further researchers are needed in relation to other important bioactive compounds present in strawberry fruits (i.e. ellagitannins), this study provides relevant commercial information that could be of great interest for both fresh and processed strawberry industry as functional foods.

\section{Acknowledgments}

This work was financially supported by the Instituto Politécnico Nacional (IPN) (Grant No. 472993), the Consejo Nacional de Ciencia y Tecnología (SAGARPA CONACYT; P. 2012-06-190290), and the Consejería de Economía, Innovación, Ciencia y Empleo, Junta de Andalucía (P. P11-AGR-7843). Rebeca Fernández Lara acknowledges a study grant from CONACYT, and a mobility grant from AUIP. Francisco J. Rodríguez-Pulido also thanks VPPI-Universidad de Sevilla for a postdoctoral grant. Authors are indebted to the staff of Biology Service (SGI, Universidad de Sevilla) for the technical assistance.

\section{References}

Aaby, K., Mazur, S., Nes, A., \& Skrede, G. (2012). Phenolic compounds in strawberry (Fragaria $x$ ananassa Duch.) fruits: Composition in 27 cultivars and changes during ripening. Food Chemistry, 132, 86-97.

Basu, A., Nguyen, A., Betts, N.M., \& Lyons, T.J. (2014). Strawberry as a functional food: An evidence-based review. Critical Review in Food Science and Nutrition, 5, 790-806.

Bestfleisch, M., Möhring, J., Hanke, M.V., Peil, A., \& Flachowsky, H. (2014). A diallel crossing approach aimed on selection for ripening time and yield in breeding of new strawberry (Fragaria x ananassa Duch.) cultivars. Plant Breeding, 133, 115-120.

Bursac Kovacevic, D., Putnik, P., Dragovic-Uzelac, Vahcic, N., Babojelic, M.S., \& Levaj, B. (2015). Influences of organically and conventionally grown strawberry cultivars on anthocyanins content and color in purees and low-sugar jams. Food Chemistry, 181 94-100.

Carazzone, C., Mascherpa, D., Gazzani, G., \& Papetti, A. (2013). Identification of phenolic constituents in red chicory salads (Cichorium intybus) by high-performance liquid chromatography with diode array detection and electrospray ionisation tandem mass spectrometry. Food Chemistry, 138, 1062-1071.

Dávalos-González, P.A., Jofre-Garfias, A.E., Hernández-Razo, A.R., Narro-Sanchez, J., Castro-Franco, J., Vázquez-Sánchez, N., \& Bujanos-Muñiz, R. (2006). Strawberry breeding for the Central Plateau of México. Acta Horticulturae, 708, 547-552.

Dávalos-González, P.A., Narro-Sánchez, J., Jofre-Garfias, A.E., Razo, A.R.H., \& VázquezSánchez, M.N. (2009). Strawberry genotypes selection for high productivity and fruit size. Acta Horticulturae, 842, 435-438.

Dávalos-González, P.A., Narro-Sánchez, J., Jofre-Garfías, A.E., Vázquez-Sánchez, M.N., \& Hernández-Razo, A.R. (2014). Yield performance assay and fruit quality of strawberry genotypes tolerant and susceptible to Fusarium oxysporum and to a viral complex. Acta Horticulturae, 1049, 263-266.

De Bruijn, J., \& Bórquez, R. (2014). Quality retention in strawberries dried by emerging dehydration methods. Food Research International, 63, 42-48.

Diamanti, J., Mazzoni, L., Balducci, F., Capelletti, R., Capocasa, F., Battino, M., Dobson, G., Stewart, D., \& Mezzetti, B. (2014). Use of wild genotypes in breeding program 
increases strawberry fruit sensorial and nutritional quality. Journal of Agricultural and Food Chemistry, 62, 3944-3953.

Food and Agriculture Organization of the United Nations (2015). Available from: http:/ faostat3.fao.org/home/E

Giampieri, F., Alvarez-Suarez, J.M., \& Battino, M. (2014). Strawberry and human health: Effects beyond antioxidant activity. Journal of Agricultural and Food Chemistry, 62, 3867-3876.

Häkkinen, S., Heinonen, M., Kärenlampi, S., Mykkänen, H., Ruuskanen, J., \& Törrönen, R. (1999). Screening of selected flavonoids and phenolic acids in 19 berries. Food Research International, 32, 345-353.

Häkkinen, S.H., \& Törrönen, A.R. (2000). Content of flavonols and selected phenolic acids in strawberries and Vaccinium species: Influence of cultivar, cultivation site and technique. Food Research International, 33, 517-524.

Heredia, F.J., Escudero-Gilete, M.L., Hernanz, D., Gordillo, B., Meléndez-Martínez, A.J., Vicario, I.M., \& González-Miret, M.L. (2010). Influence of the refrigeration technique on the colour and phenolic composition of syrah red wines obtained by prefermentative cold maceration. Food Chemistry, 118, 377-383.

Hernanz, D., Recamales, M.A., Meléndez-Martínez, A.J., Gonzalez-Miret, M.L., \& Heredia, F.J. (2007). Assessment of the differences in the phenolic composition of five strawberry cultivars (Fragaria $x$ ananassa Duch.) grown in two different soilless systems. Journal of Agricultural and Food Chemistry, 55, 1846-1852.

Hernanz, D. Recamales, A.F. Meléndez-martínez, AJ González-miret, M.L \& Heredia, F. (2008). Multivariate statistical analysis of the color-anthocyanin relationships in different soilless-grown strawberry genotypes. Journal of Agricultural and Food Chemistry, 56, 2735-2741.

Holzwarth, M., Korhummel, S., Carle, R., \& Kammerer, D.R. (2012). Evaluation of the effects of different freezing and thawing methods on color, polyphenol and ascorbic acid retention in strawberries (Fragaria $x$ ananassa Duch.). Food Research International, 48, 241-248.

Hutchings, J., \& Luo, R. (2002). Calibrated colour imaging analysis of food. In D. MacDougall (Ed.), Color in food: Improving quality (pp. 352-364). Woodhead Publishing.

Landete, J.M. (2011). Ellagitannins, ellagic acid and their derived metabolites: A review about source, metabolism, functions and health. Food Research International, 44, $1150-1160$.
Lopes da Silva, F., Escribano-Bailón, T., Pérez Alonso, J.J., Rivas-Gonzalo, J.C., \& SantosBuelga, C. (2007). Anthocyanin pigments in strawberry. LWT Food Science and Technology, 40, 374-382.

Martínez, J.A., Melgosa, M., Pérez, M.M., Hita, E., \& Negueruela, A.I. (2001). Note. Visual and instrumental color evaluation in red wines. Food Science and Technology International, 7, 439-444.

Martínez-Bolaños, M., Nieto-Angel, D., Téliz-Ortiz, D., Vaquera-Huerta, H., \& Carrillo Mendoza, O. (2008). Quality comparison of Mexican and American strawberries (Fragaria x ananassa Duch) varieties. Revista Chapingo Serie Horticultura, 14, 113-119.

Narro-Sánchez, J., Dávalos-González, P.A., Velásquez-Valle, R., \& Castro-Franco, J. (2006). Main strawberry diseases in Irapuato, Guanajuato and Zamora, Michoacan, Mexico. Acta Horticulturae, 708, 167-171.

Pérez-Jiménez, J., Neveu, V., Vos, F., \& Scalbert, A. (2010). Identification of the 100 richest dietary sources of polyphenols: An application of the phenol explorer database. European Journal of Clinical Nutrition, 64, 112-120.

Prasath, G.S., \& Subramanian, S.P. (2014). Antihyperlipidemic effect of fisetin, a bioflavonoid of strawberries, studied in streptozotocin-induced diabetic rats. Journal of Biochemical and Molecular Toxicology, 28, 442-449.

Qin, Y., Teixeira da Silva, J.A., Zhang, L., \& Zhang, S. (2008). Transgenic strawberry: State of the art for improved traits. Biotechnology Advances, 26, 219-232.

Rodríguez-Pulido, F.J., Gordillo, B., González-Miret, M.L., \& Heredia, F.J. (2013). Analysis of food appearance properties by computer vision applying ellipsoids to colour data. Computers and Electronics in Agriculture, 99, 108-115.

StatSoft. Inc. (2007). STATISTICA (data analysis software system, version 8), Tulsa, OK, USA. www.statsoft.com

Sun, J., Chu, Y.F., Wu, X., \& Liu, R.H. (2002). Antioxidant and antiproliferative activities of common fruits. Journal of Agricultural and Food Chemistry, 50, 7449-7454.

Sun, J., Liu, X., Yang, T., Slovin, J., \& Chen, P. (2014). Profiling polyphenols of two diploid strawberry (Fragaria vesca) inbred lines using UHPLC-HRMSn. Food Chemistry, 146, 289-298. 